\title{
Processing speed, executive function, and age differences in remembering and knowing
}

Article

Accepted Version

Bunce, D. and Macready, A. (2005) Processing speed, executive function, and age differences in remembering and knowing. Quarterly Journal of Experimental Psychology Section A Human Experimental Psychology, 58 (1). pp. 155168. ISSN 0272-4987 doi:

https://doi.org/10.1080/02724980443000197 Available at https://centaur.reading.ac.uk/40572/

It is advisable to refer to the publisher's version if you intend to cite from the work. See Guidance on citing.

Published version at: http://www.tandfonline.com/doi/pdf/10.1080/02724980443000197

To link to this article DOI: http://dx.doi.org/10.1080/02724980443000197

Publisher: Psychology Press

All outputs in CentAUR are protected by Intellectual Property Rights law, including copyright law. Copyright and IPR is retained by the creators or other copyright holders. Terms and conditions for use of this material are defined in the End User Agreement. 


\section{CentAUR}

Central Archive at the University of Reading

Reading's research outputs online 
Processing speed, executive function, and age differences in remembering and knowing

David Bunce and Anna Macready

Goldsmiths College, University of London

Appears in QUARTERLY JOURNAL OF EXPERIMENTAL PSYCHOLOGY (2005)

Mailing address: Department of Psychology, Goldsmiths College, University of London, London, SE14 6NW, UK. E-mail d.bunce@gold.ac.uk

For further reprinting or re-use, please contact the publisher: Lawrence Erlbaum Associates, Inc. At http://www.routledge.com/ 
Processing speed, executive function, and age differences in remembering and knowing

\begin{abstract}
A group of young $(\underline{\mathrm{n}}=52, \underline{\mathrm{M}}=23.27$ years $)$ and old $(\underline{\mathrm{n}}=52, \underline{\mathrm{M}}=68.62$ years $)$ adults studied two lists of semantically unrelated nouns. For one list $2 \mathrm{~s}$ were allowed for encoding, and for the other, $5 \mathrm{~s}$. A recognition test followed where participants classified their responses according to Gardiner's (1988) remember-know procedure. Age differences for remembering and knowing were minimal in the faster $2 \mathrm{~s}$ encoding condition. However, in the longer $5 \mathrm{~s}$ encoding condition, younger persons produced significantly more remember responses, and older adults a greater number of know responses. This dissociation suggests that in the longer encoding condition, younger adults utilized a greater level of elaborative rehearsal governed by executive processes, whereas older persons employed maintenance rehearsal involving short-term memory. Statistical control procedures however, found that independent measures of processing speed accounted for age differences in remembering and knowing, and that independent measures of executive control had little influence. The findings are discussed in the light of contrasting theoretical accounts of recollective experience in old age.
\end{abstract}


Tulving's (1985) distinction between autonoetic and noetic forms of consciousness has provided the conceptual basis for a substantial amount of research into episodic memory. Autonoetic consciousness is associated with the type of memory that allows us to intimately recreate and relive subjective experiences in our past. By contrast, noetic consciousness accompanies memories related to the storage of knowledge and facts in the absence of such intimate recollections of their acquisition. This distinction forms the basis of Gardiner's (1988) operational classification that separates recognition memory into remembering and knowing. Gardiner and Richardson-Klavehn (2000) propose that remembering involves autonoetic consciousness and relates to personal experiences of the past that recreate previous events and experiences with a clear sense of intimately reliving them. In contrast, knowing involves noetic consciousness and concerns knowledge that is held in a more impersonal way, and does not possess the awareness of reliving events and experiences.

Although an accumulating body of research has investigated age in relation to remembering and knowing, there is good reason for further work in the area. For instance, the proposition that autonoetic and noetic forms of consciousness are supported by differing neural mechanisms (Wheeler, Stuss, \& Tulving, 1997), suggests that valuable insights may be gained into aging processes by investigating remembering and knowing in young and old adults. Additionally, several studies have set out to explain age differences in remembering and knowing by taking into account measures of executive or frontal lobe function (Bunce, 2003; Parkin \& Walter, 1992; Perfect \& Dasgupta, 1997; Perfect, Williams, \& AndertonBrown, 1995), processing speed (Loevden, Roennlund, \& Nilsson, 2002), or by investigating both types of measure (Clarys, Isingrini, \& Gana, 2002). In the present study, we extend this work by investigating age variation in remembering and knowing having experimentally varied the time allowed for encoding operations. By taking into account independent measures of executive function and processing speed, we seek to shed further light on the mechanisms that underlie recollective experience in old age.

A review of the existing literature suggests that although some studies have found an age-related decrease in remembering (e.g., Bunce, 2003; Loevden, et al., 2002; Parkin \& Walter, 1992; Perfect \& Dasgupta, 1997; Perfect et al., 1995, exp 1; Schacter et al., 1997), others have not (e.g., Mark \& Rugg, 1998; Perfect et al., 1995, exp 2). One explanation for the minimal age variance found in some studies may stem from the type of processing required during encoding operations. For example, although Perfect and Dasgupta (1997) found an overall age effect for remembering, that effect was minimal when the degree of elaboration at encoding was taken into account; the greater the depth of encoding in older 
persons, the more age differences in recollective experience were minimized. Similarly, the provision of cognitive or environmental support at encoding in order to structure or enhance the depth of processing, attenuates age differences relative to conditions where no such support was provided (Loevden et al., 2002). Indeed, cognitive support at encoding was found to be particularly beneficial to remembering in older adults of lower frontal lobe function (Bunce, 2003). Turning to research findings for know responses, again the evidence is inconsistent in that some studies suggest this type of recognition to increase with age (Parkin \& Walter, 1992; Perfect et al., 1995), whereas others do not (e.g., Bunce, 2003; Mark \& Rugg, 1998; Perfect \& Dasgupta, 1997). Here too there is the suggestion that elaboration or structuring at encoding moderates age differences (Perfect et al., 1995), presumably due to the greater depth of encoding such cognitive operations involve. In sum, it appears that there are inconsistencies in findings relating to age differences in both remembering and knowing. However, there is evidence to suggest that elaboration or structuring of information at encoding may be influential in determining age differences in both types of recognition.

Regarding underlying neural mechanisms, Wheeler et al. (1997) suggest that one of the key roles played by the anterior regions of the frontal cortex is to confer conscious awareness, or autonoetic consciousness, on episodic memory. This facilitates the ability to intimately relive the past that Gardiner and Richardson-Klavehn (2000) refer to. The role of the prefrontal cortex in remembering, or recollective experience, is supported by imaging work showing right dorsolateral activation during recollection of the sociotemporal context of a word's previous occurrence (Henson, Rugg, Shallice, Josephs, \& Dolan, 1999). Indeed, it is suggested that prefrontal involvement in encoding operations such as semantic elaboration and organization (both conscious processes) provide inputs to the medial temporal system (Brewer, Zhao, Desmond, Glover, \& Gabrieli, 1998; Wagner, Schacter, Rotte, et al., 1998), an area displaying elevated activation during recollective experience (Eldridge, Knowlton, Furmanski, Bookheimer, \& Engel, 2000). However, the prefrontal cortex undergoes some of the most marked neurological changes with age (Uylings \& de Brabander, 2002), and theoretically such changes have been held to account for many of the cognitive deficits exhibited in old age (West, 1996). Given the putative role of the prefrontal cortex in conferring autonoetic consciousness during remembering, the foregoing suggests that age differences in remembering will be accounted for by individual differences in executive or frontal lobe measures. The few studies that have investigated this possibility have produced conflicting results, in that two (Bunce, 2003; Parkin \& Walter, 1992) have found evidence that measures of frontal lobe functioning account for age differences in 
remembering, and others have found weak (Perfect \& Dasgupta, 1995), or no evidence (Perfect et al., 1997). The reason for these discrepant findings is not immediately clear as in all these studies, age ranges have been similar, word lists have been used, and there has been considerable overlap in behavioral measures of frontal lobe function. Additional research is required, not least because all of those studies are confirmatory in nature (Parkin \& Java, 2000; Perfect, 1997). That is, the explanatory value of executive or frontal lobe measures was not contrasted with measures arising from other theoretical perspectives of cognitive aging. For instance, Salthouse (e.g., 1991) has argued that general processing speed accounts for much of the age-related variance in memory and other cognitive domains, and has produced numerous empirical investigations that support this view (see Salthouse, 1996). In relation to recollective experience, one study found that age differences in remembering were eliminated after controlling for processing speed (Loevden et al., 2002), and another that took both working memory and processing speed into account (Clarys et al., 2002), concluded that the latter construct was more influential in explaining age variance in remembering.

In the present study we gathered further evidence of relations between processing speed, executive function and age differences in remembering and knowing. In the experiment, participants performed in two conditions where either $2 \mathrm{~s}$ or $5 \mathrm{~s}$ were allowed for encoding semantically unrelated words. Previous research (Gardiner, Gawlik, \& RichardsonKlavehn, 1994) led us to expect that the longer encoding time would enable a greater level of elaborative rehearsal and structuring of information. Because these cognitive operations require executive processes supported by the neural structures of the prefrontal cortex, a greater level of remembering was expected in this condition. Indeed, Gardiner and colleagues demonstrated that extended encoding time is associated with enhanced recollective experience in younger adults. However, none of the previous studies that have manipulated encoding time in respect to recognition in older adults (e.g., Craik \& Rabinowitz, 1985; Wahlin, Backman, \& Winblad, 1995) have distinguished between remembering and knowing. Although there is no empirical evidence of whether additional encoding time will enhance older adults' recollective experience, frontal lobe accounts of cognitive aging (West, 1996) suggest that older persons would be less likely to initiate the elaborative rehearsal and structured encoding strategies that may aid conscious awareness and, therefore, produce fewer remember responses in the longer encoding condition. Regarding age variation in know responses, the absence of any form of cognitive support to guide elaboration and structuring of encoded information in either condition suggests that a greater proportion of know responses would be found in older persons. According to Gardiner et al. (1994), such 
responding is underpinned by maintenance rehearsal in longer encoding conditions. These predictions were tested in a sample of younger and older adults. In addition, we recorded independent measures of processing speed and executive function. This allowed us to assess how far age differences in remembering and knowing were associated with elaborative processes related to executive control, or the capacity to process information more rapidly.

Method

\section{$\underline{\text { Participants }}$}

One hundred and four persons (49 men) participated in the study, divided into younger $(\underline{\mathrm{n}}=$ 52 , aged 18 to 36 years) and older ( $\underline{n}=52$, aged 61 to 78 years) age groups. Younger adults were students of the University of London, and older participants were recruited through advertising and contacts at local church groups and charity organizations. The older participants predominantly came from professional backgrounds, and the two age groups were screened using the National Adult Reading Test (NART) Full Scale IQ (Nelson, 1982). Adults over 65 were screened also for signs of dementia using the Mini-Mental State Examination (MMSE: Folstein, Folstein, \& McHugh, 1975). All those taking part in the present study scored 25 or more on that measure. Demographic data for the two age groups are presented in Table 2.

\section{Materials}

Episodic memory task. Two lists of 12 semantically unrelated concrete nouns were prepared. In one condition, at study, words from one of the lists were presented individually, and bimodally (spoken by the experimenter, and presented on cards simultaneously) for $2 \mathrm{~s}$ each. In the other condition, words from the other list were presented bi-modally but for $5 \mathrm{~s}$ each. Lists used for the faster and slower encoding conditions, and the order in which conditions were administered, were counterbalanced within each age group. Participants performed both conditions during a single experimental session.

A recognition test was administered after participants had completed a distracter task (one of either the executive function or processing speed tasks detailed below) lasting approximately four minutes. The 12 words were intermixed with 12 "lure" concrete nouns. Participants circled items they recognized, and in doing so, classified them as either "remember" or "know" following the procedure described by Gardiner (1988). The 48 words used in the experiment fell within the frequency range of 401 to 792 words per million $(\underline{\mathrm{M}}=$ $550.35)$. 
Executive function tasks. Two measures relating to frontal and executive function were administered. In the FAS Word Fluency Test (Benton, Hamsher, Varney \& Spreen, 1983), participants orally generated as many words as possible beginning with either F, A, and S. One minute was allowed for each letter. Names of places or people, and multiple words with the same root, were disallowed. The total score for the three letters is reported here. The second task was the backward digit-span ( $\underline{B D S})$ subtest of the Wechsler Adult Intelligence Scale-R (WAIS-R: Wechsler, 1981). Here, participants were required to repeat in reverse order sequences of digits that increased in length from the initial trial of two digits. For each sequence length, two trials were administered, and a score of 1 was awarded for each correct trial. The test terminated if both trials in a particular sequence were incorrect.

Processing speed. Two measures were used to assess this construct. The first was the digit-symbol substitution subtest of the WAIS. The task involved a sheet of paper upon which a table of paired digits and symbols was displayed. Below the table were rows of paired boxes. In the upper box a digit was displayed and the participant's task was to fill in the blank lower box with the appropriate symbol from the table. Ninety seconds were allowed for the task, and the final score was the number of correctly completed symbols in that time.

The second task was a PC-administered four-choice reaction time task based upon that of Bunce, Barrowclough, and Morris (1996). Briefly, four black circles appeared psuedorandomly in one of four positions either left or right, or above or below, a central fixation cross on the PC screen. Participants responded by pressing spatially corresponding keyboard keys ( $\mathrm{S}=$ left upper; $\mathrm{C}=$ left lower; $\mathrm{L}=$ right upper; $\mathrm{M}=$ right lower) with the middle and index fingers of their left and right hands. Twenty practice trials were administered, followed by 100 test trials. Speed and accuracy were emphasized in the instructions. Here we present mean reaction time for correct responses.

\section{$\underline{\text { Procedure }}$}

Participants attended the laboratory by appointment. On arrival they completed an informed consent form, and then those aged 65 and over were screened using the MMSE. At this point, several physiological measures were recorded relating to another part of the study. A selfcompletion questionnaire recording biographical information was administered, followed by the NART. Participants then performed the first of the two recognition conditions $(2 \mathrm{~s}$ or $5 \mathrm{~s}$ encoding), after which processing speed and executive function measures were administered. To finish, participants performed the second recognition condition. Following debriefing, 
those who were non-students were paid $£ 6.50$ Sterling for participation. Psychology students taking part in the study received course credits required for completing their degree.

\section{Results}

Bivariate associations between the main variables in the study, and descriptive data for the recognition variables, are presented in Table 1 and 2 respectively. In Table 1 it can be seen that age was significantly associated with higher NART scores, but poorer performance on both processing speed measures. The relationships between age and executive function measures were statistically unreliable. Significant negative correlations with remember words in the $5 \mathrm{~s}$ condition suggest that older adults were less able to utilize the additional encoding time in this condition. Associations were investigated further through a series of analysis of variance (ANOVA), where condition ( $2 \mathrm{~s}$ and $5 \mathrm{~s}$ encoding time) served as the withinsubjects factor, and age (young or old) as the between-subjects factor. As preliminary T-tests found the older group recorded significantly higher NART scores $(\mathrm{p}<.01$, see Table 2$)$, that variable was entered as a covariate in all of the ANOVAs reported below. In each condition, the number of hits and false alarms were calculated for remember and know responses. Although signal detection theory metrics take response bias into account, there are uncertainties concerning their use in relation to know responses (Jacoby, Yonelinas, \& Jennings, 1997). Therefore, in order to adjust for possible response bias in the present investigation, we elected to analyse hits adjusted for false alarms (i.e. Hits - False Alarms).

Table 1 about here

\section{$\underline{\text { Remember responses }}$}

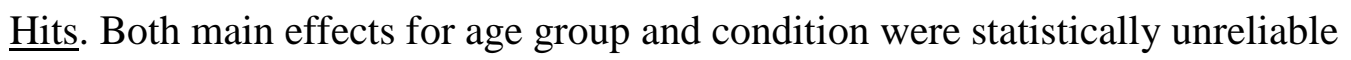
(ps>.34). However, the Age $x$ Condition interaction was significant, $F(1,101)=4.68, \eta^{2}=$ $.044, \mathrm{p}=.033$. Consideration of Table 2 suggests that although the performance of the younger group benefited when more time was allowed for encoding, that was not the case for older individuals. Pairwise comparisons confirmed this impression in that for the younger group, the $5 \mathrm{~s}$ condition produced a significantly greater number of hits than the $2 \mathrm{~s}$ condition $(p<.001)$, whereas that comparison was nonsignificant in the older group. The comparison for young and old scores in the $5 \mathrm{~s}$ condition was close to conventional levels of statistical 
reliability $(\mathrm{p}=.06)$; younger persons produced a greater number of hits. This comparison was nonsignificant in the $2 \mathrm{~s}$ condition.

False alarms. Analysis of false alarms revealed the age main effect to be significant, $\mathrm{F}(1,101)=18.35, \eta^{2}=.154, \mathrm{p}<.001$. Older adults produced a greater number of false alarms than younger adults (see Table 2). Neither the main effect for condition nor the Age $\mathrm{x}$ Condition interaction, were statistically reliable (ps>.72).

Adjusted hits. Both main effects for age and condition were statistically unreliable (ps>.16). However, the two-way interaction between those factors did attain significance, $\mathrm{F}(1,101)=4.48, \eta^{2}=.043, \mathrm{p}=.037$. Again Table 2 suggests that older individuals did not benefit from the additional encoding time in the $5 \mathrm{~s}$ encoding condition to the same extent as younger adults. A pairwise comparison between conditions was significant $(\mathrm{p}<.001)$ in the younger, but not in the older group. Although the comparison between young and old groups in the $5 \mathrm{~s}$ condition was statistical reliability $(\mathrm{p}=.023)$, it was nonsignificant in the $2 \mathrm{~s}$ condition.

In sum, the findings suggest that the longer encoding period enabled younger adults to produce a greater number of remember responses. The age difference was minimal in the 2 s encoding condition.

Table 2 about here

\section{$\underline{\text { Know responses }}$}

Hits. The main effects for age and condition failed to reach statistical significance (ps>.11). However, the Age $x$ Condition interaction was statistically reliable, $\mathrm{F}(1,101)=$ $6.46, \eta^{2}=.060, \mathrm{p}=.013$. The impression conveyed by Table 2 , that older adults produced more hits in the $5 \mathrm{~s}$ condition, was confirmed by a pairwise comparison in that group $(\mathrm{p}<.01)$. None of the other comparisons achieved statistical significance.

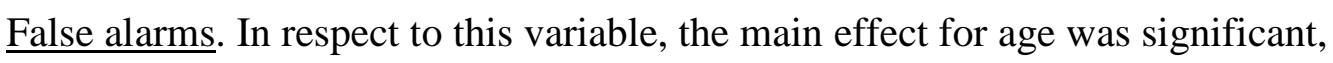
$\mathrm{F}(1,101)=4.78, \eta^{2}=.045, \mathrm{p}=.031$. Older adults produced more false alarms. However, neither the condition main effect, nor the two-way interaction, achieved statistical significance, $(\mathrm{ps}>.58)$.

Adjusted hits. Although the main effects for age and condition were both nonsignificant ( $\mathrm{ps}>.31$ ), the two-way interaction between those factors was statistically reliable, $F(1,101)=4.09, \eta^{2}=.039, p=.046$. Table 2 indicates that this was due to a higher 
number of responses produced by older persons in the $5 \mathrm{~s}$ condition. A pairwise comparison between conditions in the older group was significant $(\mathrm{p}=.029)$, whereas the equivalent comparison in the younger group was nonsignificant. The comparison between young and old in the $2 \mathrm{~s}$ condition also achieved statistical significance $(\mathrm{p}=.023)$.

To summarize, the foregoing analyses indicate that the longer encoding time resulted in a greater number of know responses in older persons. In the younger group, encoding time does not appear to have influenced this type of responding to the same degree.

Table 3 about here

The mediating role of processing speed and executive function

A major objective of the present research was to evaluate the extent to which either executive function or processing speed accounted for age differences in remembering and knowing where they were found. Before that objective was addressed however, it was important to confirm statistically that the respective variables factored appropriately. Therefore, the verbal fluency, backward digit span, digit symbol substitution, and choice RT variables were subjected to principal component analysis with varimax rotation. Two components emerged. The first related to processing speed and comprised of the digit symbol substitution and choice RT variables (explaining 37.98\% of the variance). Executive function formed the second component (verbal fluency and backward digit span), accounting for 33.10 percent of the variance. The rotated factor matrix is presented in Table 3 with the factor structures emphasized in bold. These results are consistent with the conceptual distinction made between executive function and processing speed.

Hierarchical multiple regression was used to assess the extent to which processing speed or executive function explained the significant Age $\mathrm{x}$ Encoding time interactions relating to remember and know words described earlier. Two models were evaluated. In the first, recognition scores from the $5 \mathrm{~s}$ condition were regressed on scores from the $2 \mathrm{~s}$ condition at Step 1. It is important to note that the residual from this step represents the benefits to recognition performance associated with the longer encoding condition. At Step 2, NART scores were added for control purposes due to the significant between-group differences in this variable, and at Step 3 age was entered. In Model 2, Steps 1 and 2 were the same as for Model 1. However, at Step 3 the factor scores for either processing speed or executive function were added, and at Step 4 age was entered. The two crucial elements of this procedure are that in Model 1, age at Step 3 attains statistical significance, whereas in 
Model 2 age is rendered non-significant by the inclusion of the factor scores at Step 3. The results of these analyses are presented in Table 4.

Processing speed. For remember words, the addition of age in Model 1 significantly accounted for four percent of the residual variance attributable to the longer encoding condition for both hits and adjusted hits. Notably in both analyses, when factors scores for processing speed were taken into account in Model 2, age became non-significant. In relation to know words, age significantly added three percent of the variance to hits in Model 1, and this too was rendered statistically unreliable when processing speed was controlled for. With regard to adjusted hits for know words, age failed to attain significance in Model 1.

As the two processing speed measures vary to some degree in the cognitive operations they require (the choice RT task is a relatively pure measure of psychomotor speed, whereas the digit symbol substitution task involves a substantial memory component), it was of interest to assess which of the two variables was most influential in accounting for the age-related variance. Therefore, the regression analyses were repeated, but on this occasion the raw scores for choice RT and digit symbol were added separately at Step 3. In each analysis, beta weights for choice RT were significant, whereas those for digit symbol failed to attain statistical significance. Thus, it appears that psychomotor speed was more influential in accounting for the age-related variance reported in the foregoing analyses.

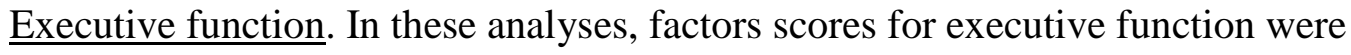
added at Step 3 of Model 2. In all analyses, they failed to account for any of the age-related variance in either remember or know words. Further analyses where the raw scores for verbal fluency and backward digit span were entered separately into the regression equations did not modify these null findings. Therefore, it appears that executive function, as measured by the variables in this experiment, does not account for age differences in the utilization of encoding time, either in respect to remember or know words.

Table 4 about here

\section{Discussion}

This is the first study to investigate age differences in remembering and knowing having manipulated the time available for encoding operations, and additionally recorded independent measures of executive function and processing speed. Two important findings were obtained. First, although age differences in remembering were minimal in the shorter 2 $\mathrm{s}$ condition, the results suggested that younger persons used the longer encoding period $(5 \mathrm{~s})$ 
more effectively, and produced significantly more correct remember responses than older adults. In contrast however, older persons produced more know responses than younger adults in that longer encoding condition. This dissociation is consistent with the view that younger persons were more able to utilize the longer encoding time to initiate elaborative rehearsal, and this was related to their greater recollective experience. By contrast, the findings suggest that older persons employed maintenance rehearsal, and this was reflected in their elevated know responding. Second, although effect sizes were modest, processing speed but not executive function explained age differences in both remembering and knowing in the longer encoding condition.

Broadly, the findings are consistent with prior research suggesting an age-related decrease in recollective experience (e.g., Bunce, 2003; Parkin \& Walter, 1992; Perfect \& Dasgupta, 1997; Perfect et al., 1995; Schacter et al., 1997), and confirm that the level of know responding increases with age in the absence of structuring that aids elaboration and organizational strategies at encoding (Perfect et al., 1995). Importantly though, the dissociation in age gradients for remember and know words in the longer encoding condition suggests that the time allowed for encoding was related to age differences in the level of conscious awareness associated with recognition. For younger adults, the results are in line with work (Gardiner et al., 1994) showing that longer encoding time, and the elevated elaborative rehearsal this allows, increases remember responding. This suggests that executive control processes governing elaborative rehearsal underpinned the observed age differences in remembering. A key question therefore, was whether the factor scores for the executive function measures accounted for the age-related variance in remembering in that longer condition. This would provide further evidence that greater elaborative rehearsal and structuring in the $5 \mathrm{~s}$ condition underpinned younger adults' greater recollective experience. The findings of the regression analyses provided little support for this proposal. Executive function factor scores failed to attenuate the age differences in remembering associated with the longer encoding condition. Instead, perceptual processing speed accounted for the agerelated variance in both remembering and knowing.

This finding is in agreement with two earlier studies that found processing speed to explain age differences in recollective experience (Clarys et al., 2002; Loevden et al., 2002). However, given the widespread evidence that declines in processing speed are one of the most marked features of cognitive aging, in the present context, it is perhaps not surprising that perceptual speed accounted for age differences in remembering and knowing in the longer encoding condition; given extra time, younger adults are able to process more 
information, and this is likely to be explained by independent measures of processing speed. The key point though, is the qualitative dissociation in conscious awareness distinguishing the two age groups. It appears that for younger adults, elaboratively processing more information resulted in a greater level of conscious awareness in recognition. For older adults, it seems that although more information was processed in the longer encoding condition, that processing was shallower, and resulted in elevated know responding. This latter finding suggests that older adults used a greater level of maintenance rehearsal. That is, non-associative rehearsal processes that serve to maintain material in short-term memory (Woodward, Bjork, \& Jongeward, 1973).

The lack of association between executive function measures and age differences in remembering was unexpected, particularly given the hypothesized relations between elaborative rehearsal and executive control. Two factors may explain this finding. First, earlier work (Bunce, 2003) has shown that the provision of cognitive support to guide elaboration and structuring attenuates remembering deficits in older adults of lower frontal lobe function. In the present experiment, cognitive support, or instructions concerning how to encode information, were not provided. It is possible therefore, that before older adults initiate elaborative rehearsal processes, some form of cue is required (e.g., explicit instructions or some form of cognitive support embedded in the to-be-remembered materials). The absence of both cognitive support and encoding instructions in the present study may account, therefore, for the minimal influence of executive control measures. Second, it is possible that, operationally, the two measures of executive function (FAS test and backward digit span) did not access the executive processes involved in elaborative rehearsal and structuring with sufficient rigour. Had a more extensive range of executive control measures been employed, it is possible that a greater proportion of the age-related variance in remembering would have been accounted for.

It is worth commenting on the finding that the purer measure of speed, the psychomotor task, accounted for age differences in remembering and knowing, whereas the digit symbol substitution task did not. Although commonly used as a measure of perceptual speed, this latter task is not particularly pure. Not only does it contain a substantial memory component but previous research (Piccinin \& Rabbitt, 1999) suggests that learning of the symbol-number combinations significantly improves performance. Such learning may involve some of the elaborative and structuring capacities held to underpin recollective experience in the present research. Therefore, the failure of this measure to account for age differences in remembering is noteworthy, as it indicates further the methodological 
difficulties associated with independent measures and their ability to capture elaborative and structuring processes.

A further possibility that requires consideration is that the psychomotor task responsible for the main mediating effect was tapping a more general factor relating to fluid intelligence. This raises the possibility that fluid intelligence underpinned the findings in respect to processing speed and as such, recent research by Duncan and colleagues (2000) is informative. They have produced imaging data suggesting selective activation of the lateral frontal cortex during a high demand fluid intelligence task. Therefore, if our measure was reflecting a higher-order general intelligence factor, it is possible that factor was supported by the neural substrates of the frontal cortex, the brain area held to sustain autonoetic consciousness during remembering.

These possibilities aside, the mixed findings with respect to executive processes in the present study limit any firm conclusions concerning the role of autonoetic consciousness in age differences in recollective experience. On the one hand, following predictions, levels of remembering were elevated in younger adults following the longer encoding time. This is consistent with the view that the hypothesized elevations in elaborative rehearsal in that condition underpinned age differences in remembering. On the other hand, the independent measures of executive function failed to account for those differences. To clarify associations further, it is important that future work employs a more extensive range of executive control measures, and includes some manipulation of encoding instructions in study conditions of varying lengths. Moreover, as noted elsewhere (Parkin \& Java, 2000; Perfect, 1997), such research should contrast further the competing theoretical accounts of age differences in recollective experience providing the focus for the present study.

Several important conclusions arise from this research. First, our findings suggest that following an experimental manipulation of the time allowed for encoding operations, a dissociation relating to the level of conscious awareness in recognition occurs in younger and older adults. Second, it appears that younger persons were able to utilize the additional encoding time to process more information to a greater depth, and therefore, report a greater level of remembering. By contrast however, although older adults processed more information, it appears that the level of processing was shallower, and in consequence a greater level of recognition in the absence of conscious awareness resulted. Finally, although executive processes were implicated in age differences in recollective experience, independent measures of perceptual speed explained those differences. Clearly, further work is required that not only evaluates the encoding conditions influencing remembering and 
knowing in older adults, but also empirically contrasts competing theoretical accounts of the cognitive processes underpinning age differences in recollective experience. 
References

Benton, A.L., Hamsher, K., Varney, N.,\& Spreen, O. (1983). Contributions to neuropsychological assessment. New York: Oxford University Press.

Brewer, J.B., Zhoa, Z., Desmond, J.E., Glover, G.H., \& Gabrieli, J.D.E. (1998). Making memories: brain activity that predicts how well visual experience will be remembered. Science, 281, 185-187.

Bunce, D. (2003). Cognitive support at encoding attenuates age differences in recollective experience among adults of lower frontal lobe function. Neuropsychology, 17, 353361.

Bunce, D., Barrowclough, A., \& Morris, I. (1996). The moderating influence of physical fitness on age gradients in vigilance and serial choice responding tasks. Psychology and Aging, 11, 671-682.

Clarys, D., Isingrini, M., \& Gana, K. (2002). Mediators of age-related differences in recollective experience in recognition memory. Acta Psychologica, 109, 315-329.

Craik, F.I.M., \& Rabinowitz, J.C. (1985). The effects of presentation rate and encoding task on age-related memory deficits. Journal of Gerontology, 40, 309-315.

Duncan, J., Seitz, R.J., Kolodny, J., Bor, D., Herzog, H., Ahmed, A., Newell, F.N., \& Emslie, H. (2000). A neural basis for general intelligence. Science, 289, 457-460.

Eldridge, L.L., Knowlton, B.J., Furmanski, C.S., Bookheimer, S.Y., Engel, S.A. (2000). Remembering episodes: a selective role for the hippocampus during retrieval. Nature Neuroscience, $3,1149-1152$.

Folstein, M.F., Folstein, S.E.,\& McHugh, P.R. (1975). "Mini-mental state”: A practical method of grading the cognitive state of patients for the clinician. Journal of Psychiatric Research, 12, 189-198.

Gardiner, J.M. (1988). Functional aspects of recollective experience. Memory and Cognition, 16, 309-313.

Gardiner, J.M., Gawlik, B., \& Richardson-Klavehn, R. (1994). Maintenance rehearsal affects knowing, not remembering; elaborative rehearsal affects remembering, not knowing. Psychonomic Bulletin \& Review, 1, 107-110.

Gardiner, J.M., \& Richardson-Klavehn, A. (2000). Remembering and knowing. In F.I.M. Craik and E. Tulving (Eds.), The Oxford handbook of memory. Oxford: Oxford University Press. 
Henson, R.N.A., Rugg, M.D., Shallice, T., Josephs, O.,\& Dolan, R.J. (1999). Recollection and familiarity in recognition memory: An event-related functional magnetic imaging study. The Journal of Neuroscience, 19, 3962-3972.

Jacoby, L.L., Yonelinas, A.P.,\& Jennings, J. (1997). The relation between conscious and unconscious (automatic) influences: A declaration of independence. In J. Cohen \& J.W. Schooler (Eds.), Scientific Approaches to Consciousness (pp. 13-47). Mahwah, NJ: Erlbaum.

Loevden, M.,Roennlund, M., \& Nilsson, L.-G. (2002). Remembering and knowing in adulthood: Effects of enacted encoding and relations to processing speed. Aging, Neuropsychology, and Cognition, 9, 184-200.

Mark, R.E., \& Rugg, M.D. (1998). Age effects on brain activity associated with episodic memory retrieval: An electrophysiological study. Brain, 121, 861-873.

Nelson, H. (1982). National Adult Reading Test (NART). Windsor, England: Nfer-Nelson.

Piccinin, A.M., \& Rabbitt, P.M.A. (1999). Contribution of cognitive abilities to performance and improvement on a substitution coding task. Psychology and Aging, 14, 539-551.

Parkin, A.J., \& Java, R.I. (2000). Determinants of age-related memory loss. In T.J. Perfect \& E.A. Maylor (Eds.), Models of cognitive aging. Oxford, UK: Oxford University Press.

Parkin, A.J. \& Walter, B.M. (1992). Recollective experience, normal aging, and frontal dysfunction. Psychology and Aging, 7, 290-298.

Perfect, T.J. (1997). Memory aging as frontal lobe dysfunction. M.A. Conway (ed.), Cognitive models of memory. Hove, UK: Psychology Press.

Perfect, T.J.,\& Dasgupta, Z.R.R. (1997). What underlies the deficit in reported recollective experience in old age? Memory and Cognition, 25, 849-858.

Perfect, T.J., Williams, R.B.,\& Anderton-Brown, C. (1995). Age differences in reported recollective experience are due to encoding effects, not response bias. Memory, 3 , 169-186.

Salthouse, T.A. (1991). Theoretical perspectives on cognitive aging. Hillsdale, NJ: Erlbaum.

Salthouse, T.A. (1996). The processing-speed theory of adult age differences in cognition. Psychological Review, 103, 403-428.

Schacter, D.L., Koutstaal, W., Johnson, M.K., Gross, M.S., \& Angell, K.E. (1997).

False recollection induced by photographs: A comparison of older and younger adults. Psychology and Aging, 12, 203-215.

Tulving, E. (1985). Memory and consciousness. Canadian Psychology, 25, 1-12. 
Uylings, H.B.M., \& de Brabander, J.M. (2002). Neural changes in normal human aging and Alzheimer's disease. Brain and Cognition, 49, 268-276.

Wahlin A., Backman, L., \& Winblad, B. (1995). Free recall and recognition of slowly and rapidly presented words in very old age: A community-based study. Experimental Aging Research, 21, 251-271.

Wagner, A.D., Schacter, D.L., Rotte, M., Koustaal, W, Maril, A, Dale, A.M., Rosen, B.R.,\& Buckner, R.L. (1998). Building memories: remembering and forgetting of verbal experiences as predicted by brain activity. Science, 281, 188-191.

Wechsler, D. (1981). WAIS-R: manual: Wechsler adult intelligence scale-revised. New York: Harcourt Brace Jovanovich.

West, R.J. (1996). An application of prefrontal cortex function theory to cognitive aging. Psychological Bulletin, 120, 272-292.

Wheeler, M.A., Stuss, D.T.,\& Tulving, E. (1997). Toward a theory of episodic memory: The frontal lobes and autonoetic consciousness. Psychological Bulletin, 121, 331-354.

Woodward, A.E., Bjork, R.A.,\& Jongeward, R.H. (1973). Recall and recognition as a function of primary rehearsal. Journal of Verbal Learning and Verbal Behavior, 12, 608-617. 
Table 1. Bivariate correlation matrix

\begin{tabular}{|c|c|c|c|c|c|c|c|c|c|c|c|c|c|c|c|c|}
\hline Variable & 1 & 2 & 3 & 4 & 5 & 6 & 7 & 8 & 9 & 10 & 11 & 12 & 13 & 14 & 15 & 16 \\
\hline 1. Age group & - & & & & & & & & & & & & & & & \\
\hline 2. Gender & -.02 & - & & & & & & & & & & & & & & \\
\hline 3. NART & $.35^{\star *}$ & -.11 & - & & & & & & & & & & & & & \\
\hline 4. Exec Func & .06 & -.07 & $.41^{* *}$ & - & & & & & & & & & & & & \\
\hline 5. FAS & .11 & -.08 & $.41^{* *}$ & $.84^{* *}$ & - & & & & & & & & & & & \\
\hline 6. BDS & -.13 & -.06 & $.20^{*}$ & $.76^{* *}$ & $.30^{\star *}$ & - & & & & & & & & & & \\
\hline 7. Speed & $-.79^{\star *}$ & .08 & $-.24^{*}$ & .00 & -.05 & $.21^{*}$ & - & & & & & & & & & \\
\hline 8. DSST & $-.65^{\star *}$ & .19 & -.11 & $.21^{*}$ & .14 & $.25^{*}$ & $.84^{* *}$ & - & & & & & & & & \\
\hline 9. 4 choice RT & $.68^{* *}$ & .06 & $-.21^{*}$ & .04 & -.02 & -.13 & $-.88^{\star *}$ & $-.50^{* *}$ & - & & & & & & & \\
\hline 10. $R$ hits $2 s$ & .00 & $.24^{*}$ & -.05 & -.03 & .00 & -.03 & .14 & .12 & -.13 & - & & & & & & \\
\hline 11. $R$ hits $5 \mathrm{~s}$ & $-.21^{*}$ & .13 & -.12 & .04 & .09 & .04 & $.24^{*}$ & .14 & $-.30^{\star *}$ & $.53^{\star *}$ & - & & & & & \\
\hline 12. Adj R hits $2 s$ & -.03 & $.23^{*}$ & -.02 & -.01 & .02 & -.01 & .19 & .15 & -.17 & $.99^{\star *}$ & $.52^{\star *}$ & - & & & & \\
\hline 13. Adj R hits $5 \mathrm{~s}$ & $-.24^{*}$ & .13 & -.09 & .05 & .10 & .05 & $.27^{\star *}$ & .15 & $-.33^{\star *}$ & $.53^{\star *}$ & $.99^{\star * *}$ & $.53^{\star *}$ & - & & & \\
\hline 14. $K$ hits $2 \mathrm{~s}$ & -.07 & $-.22^{*}$ & $.22^{*}$ & .06 & .01 & .07 & .03 & .08 & .02 & $-.66^{\star *}$ & $-.45^{\star *}$ & $-.63^{\text {** }}$ & $-.43^{\star *}$ & - & & \\
\hline 15. $\mathrm{K}$ hits $5 \mathrm{~s}$ & .13 & -.08 & .13 & -.06 & -.08 & -.05 & -.12 & -.05 & .18 & $-.50^{\text {** }}$ & $-.87^{\star *}$ & $-.47^{\text {** }}$ & $-.85^{\star *}$ & $.53^{\star *}$ & - & \\
\hline 16. Adj K hits $2 s$ & -.12 & $-.25^{\star *}$ & $.23^{*}$ & .07 & .04 & .07 & .06 & .09 & -.02 & $-.65^{\star *}$ & $-.44^{\star *}$ & $-.61^{\star *}$ & $-.42^{\star *}$ & $.96^{* *}$ & $.52^{\star \star}$ & - \\
\hline 17. Adj $\mathrm{K}$ hits $5 \mathrm{~s}$ & .06 & -.06 & .14 & -.06 & -.07 & -.05 & -.05 & .00 & .10 & $-.34^{* *}$ & $-.78^{\star \star}$ & $-.36^{* *}$ & $-.75^{\star *}$ & $.50^{\star *}$ & $.92^{* *}$ & $.52^{\star *}$ \\
\hline
\end{tabular}

Notes. NART = National Adult Reading Test; FAS = Verbal fluency; BDS = Backward digit span; DSST = Digit symbol substitution task; R $=$ Remember; $\mathrm{K}=$ know; Adj = Adjusted; Variables 4 and 7 are based upon factor scores

${ }^{*} p<.05 ;{ }^{* *} p<.01$ 
Table 2. Means scores (SD) for demographic, executive function, processing speed, and recognition variables for young and old groups

Demographic

Age

Women (\%)

NART
Young

$23.27(4.86)$

53.85

$107.52(8.20)$
Old

68.62 (4.30)

51.92

114.06 (9.69)
Overall

45.94 (23.24)

52.89

110.79 (9.52)

$45.04(8.06)$

$6.58(1.81)$

$43.83(11.42)$

$42.62(10.24)$

$7.06(1.98)$

$71.42(10.94)$

381.01 (52.96)

52.29 (11.38)

503.05 (78.31)

$61.86(14.69)$

442.03 (90.47)

Remember

Hits

$$
2 \mathrm{~s}
$$

$5.81(3.33)$

7.40 (3.26)

5.82 (3.39)

$5.98(3.40)$

$5.82(3.34)$

6.69 (3.39)

False alarms $2 \mathrm{~s}$

$0.12(0.32)$

$0.04(0.19)$

$0.31(0.61)$

$0.23(0.51)$

$0.22(0.50)$

$5 \mathrm{~s}$

5.69 (3.35)

7.37 (3.25)

$5.51(3.41)$

$5.75(3.41)$

$0.14(0.40)$

Adjusted hits $2 \mathrm{~s}$

$5 \mathrm{~s}$

Know

Hits

$2 \mathrm{~s}$
$5 \mathrm{~s}$

3.19 (2.50)

2.96 (2.74)

$2.82(2.53)$

$3.69(3.10)$

3.01 (2.51)

$3.33(2.93)$

False alarms $2 \mathrm{~s}$

$0.37(0.69)$

$0.61(0.77)$

$0.65(1.66)$

$0.49(0.74)$

$0.33(0.97)$

$2.22(2.44)$

$3.04(3.66)$
$5.60(3.37)$

$6.56(3.41)$
Adjusted hits $2 \mathrm{~s}$

$2.83(2.52)$

$2.64(3.04)$

Note. NART: National Adult Reading Test DS: Digit span

CRT: Choice reaction time 
Table 3. Principal component analysis rotated factor matrix

\section{$\underline{\text { Component }}$}

\section{Processing speed Executive function}

$\begin{array}{lrl}\text { FAS } & -.046 & .836 \\ \text { Backward DS } & .206 & .763 \\ \text { Digit symbol } & .837 & .207 \\ \text { CRT } & -.880 & .037\end{array}$

Note.

FAS: Verbal fluency

DS: Digit span

CRT: Choice reaction time

Factor structures emphasized in bold 
Table 4. Hierarchical multiple regression: The mediating influence of processing speed on age differences in remembering and knowing

$\underline{\text { Remember }}$

\begin{tabular}{rrrrrr}
\multicolumn{3}{c}{ Model 1 } & \multicolumn{3}{c}{ Model $2^{\mathrm{A}}$} \\
\hline Step & Beta & $\Delta \mathrm{R}^{2}$ & Step & Beta & $\Delta \mathrm{R}^{2}$ \\
\hline
\end{tabular}

DV $=$ Hits $5 \mathrm{~s}$

$\begin{array}{lcc}\text { 1. Hits 2 s } & .53 & .28^{\star \star \star} \\ \text { 2. NART } & -.09 & .01 \\ \text { 3. Age gp } & -.21 & .04^{\star}\end{array}$

3. Speed $\quad .16$

3. Age gp

4. Age gp $\quad-.20$

DV = Adj Hits $5 \mathrm{~s}$

$\begin{array}{lcc}\text { 1. Adj Hits 2s } & .53 & .28^{* *} \\ \text { 2. NART } & -.08 & .01 \\ \text { 3. Age gp } & -.22 & .04^{* *}\end{array}$

3. Speed $\quad .16$

.03

2. NART

$-.22$

4. Age gp $\quad-.24$

.02

Know

$\begin{array}{lllllll}\text { DV = Hits } 5 \mathrm{~s} & \text { 1. Hits 2 s } & .53 & .28^{* * *} & \text { 3. Speed } & -.14 & .02 \\ & \text { 2. NART } & .01 & .00 & 4 . \text { Age gp } & .18 & .01 \\ & \text { 3. Age gp } & .19 & .03^{*} & & & \\ \text { DV = Adj Hits 5 s } & \text { 1. Adj Hits 2 s } & .52 & .27^{* * *} & & & \\ & \text { 2. NART } & .02 & .00 & & \\ \text { 3. Age gp } & .14 & .02 & & \end{array}$

Notes.

Step $1 \mathrm{df}=1,102 ;$ Step $2 \mathrm{df}=1,101 ;$ Step $3 \mathrm{df}=1,100 ;$ Step $4 \mathrm{df}=1,99$

${ }^{*} p<.05 ;{ }^{* *} p<.02 ;{ }^{* * *} p<.01$

A. In Model 2, Steps 1 and 2 are as in Model 1

Adj = Adjusted; gp = group 